\title{
OS DESCRITORES DA PROVA BRASIL E O LIVRO DIDÁTICO DE LÍNGUA PORTUGUESA: UM ESTUDO DE CASO
}

\section{PROVA BRASIL DESCRIPTORS AND THE PORTUGUESE LANGUAGE DIDATIC BOOK: A CASE STUDY}

Marciane Cocchi Dorta ${ }^{1}$ Andréia Cunha Malheiros Santana ${ }^{2}$

\begin{abstract}
Resumo: Esta pesquisa é fruto do Mestrado Profissional em Letras (ProfLetras) e reflete um pouco da realidade do professor da educação básica. A proposta de intervenção buscou identificar quais descritores de Língua Portuguesa cobrados na ANRESC/Prova Brasil apresentaram dificuldades para os alunos de um nono ano de uma escola pública do Norte do Paraná e como esses descritores foram tratados pelo livro didático adotado pela instituição de ensino. Após o levantamento de dados, a intenção final desta pesquisa era socializar os resultados com os professores a fim que eles compreendam plenamente o contexto de implantação das avaliações externas, bem como as limitações do livro didático ao trabalhar os conteúdos cobrados no referido exame. A partir dos resultados, constatou-se que o livro didático analisado traz todos os descritores da Prova, porém com uma abordagem diferente da empregada no referido exame, sem testes no material didático, com pouco diálogo entre a linguagem verbal e suas diferentes variações, o que pode trazer algum tipo de dificuldade aos alunos ao realizarem o teste, espera-se que tais resultados sejam discutidos com o corpo docente da escola e possibilitem que estes compreendam de maneira mais plena a Prova Brasil.
\end{abstract}

Palavras-chave: Prova Brasil, descritores, livro didático

Abstract: This research is the result of the Professional Masters in Letters (ProfLetras) and reflects a little of the reality of the teacher of basic education. The intervention proposal sought to identify which Portuguese Language descriptors collected in ANRESC / Prova Brasil

\footnotetext{
1 Professora; mestre em Letras pela Universidade Estadual de Londrina (UEL). E-mail: profmarciane@hotmail.com
}

\footnotetext{
${ }^{2}$ Possui graduação em Letras pela Universidade Estadual Paulista Júlio de Mesquita Filho (1998), Mestrado (2003) e Doutorado (2010) em Educação Escolar, também pela UNESP. No mestrado, desenvolveu uma pesquisa sobre a importância dos estágios na formação dos licenciados do curso de Letras e, no doutorado, pesquisou sobre as necessidades de formação continuada dos gestores e professores de português e inglês da rede pública. Além disso, cursou Pedagogia (2009) e participa dos grupos de estudos e pesquisas GEPFEC (Grupo de Estudos e Propostas sobre a Formação do Professor Contemporâneo- UNESP), FELIP (Formação e Ensino em Língua PortuguesaUEL) e Observatório e pesquisa das políticas de avaliação da educação superior (POW1 - UFSCar). Em 2013, concluiu o Pós-Doc, na UFSCar, desenvolvendo uma pesquisa sobre a relação entre as avaliações externas, as políticas públicas, a formação continuada dos professores e a melhoria da qualidade na escola pública, com apoio financeiro da FAPESP. Atualmente, é professora adjunta na Universidade Estadual de Londrina (UEL), na qual atua diretamente na formação de professores, integrando o corpo docente do Programa de Pós-Graduação em Educação e do mestrado profissional ProfLetras, respondendo pela coordenação deste. E-mail: andreiacunhamalheiros@gmail.com
} 
presented difficulties for the students of a ninth grade of a public school in the North of Paraná and how these descriptors were treated by the textbook adopted by the educational institution. After the data collection, the final intention of this research was to socialize the results with the teachers so that they fully understand the context of implantation of the external evaluations, as well as the limitations of the didactic book when working the contents charged in the said examination. From the results, it was verified that the didactic book analyzed has all the descriptors of the Test, but with a different approach from the one used in the exam, without tests in the didactic material, with little dialogue between the verbal language and its different variations, the which may bring some kind of difficulty to the students during the test, it is expected that such results will be discussed with the faculty of the school and enable them to fully understand the Prova Brasil.

Keywords: "Prova Brasil"; descriptors; didactic book

\section{Introdução}

A formação de professores é uma questão chave para melhorar a qualidade da educação brasileira, neste cenário surge o Profletras, uma iniciativa em âmbito nacional, destinada aos professores da rede pública de ensino, mais precisamente ao ciclo II do ensino fundamental. Diferentemente, do mestrado acadêmico, o Profletras determina que o estudante realize uma pesquisa de natureza interpretativa e interventiva, tendo como foco de investigação um problema da realidade escolar, este é um diferencial importantíssimo, pois ele atende a uma clientela que tem vínculo com a rede pública e deve articular pesquisa/estudo e seu contexto de trabalho, a fim de melhorá-lo, a pesquisa deve ser concernente ao ensino e à aprendizagem na disciplina de Língua Portuguesa no Ensino Fundamental.

Articular esta formação continuada aos problemas vivenciados na realidade escolar e mais do que isto, buscar apresentar dados/informações que contribuíssem para o bom trabalho do professor foi o nosso norteador para a escolha do tema trabalhado, optamos por investigar as avaliações externas, mais precisamente a Prova Brasil, partindo do que apregoa o Profletras, foi escolhida a nossa realidade local e selecionamos as dificuldades vivenciadas pelos estudantes, em seguida, investigamos como o livro didático trabalhava estes descritores, partimos da ideia de que o livro didático tem uma influência inegável para o trabalho do professor e, por isso optamos por analisar as suas lacunas, para que depois pudéssemos socializar isto com os professores em forma de minicurso realizado durante as ATPCS (aula de trabalho pedagógico coletivo). O objetivo desse trabalho foi investigar quais descritores da Prova Brasil (ANRESC) apresentaram dificuldades para os alunos de uma determinada escola pública do Norte do Paraná na avaliação de 2013 e como estes descritores dialogam com os 
conteúdos abordados pelo livro didático adotado pela instituição de ensino, após esta fase, os dados coletados seriam socializados com os professores desta escola. O problema levantado era se existiria relação entre os conteúdos cobrados na Prova Brasil e aqueles abordados pelo livro didático, a preocupação central era saber se o material didático mais comumente utilizado em sala de aula (o livro didático) abordava os mesmos descritores exigidos no exame e depois socializar os dados encontrados com os demais professores da escola, pois a nossa vivência em sala de aula nos mostrou que muitos não entendiam o que eram os descritores das avaliações externas, nem se eles trabalhavam com tais descritores. Neste sentido, o projeto de intervenção realizado durante o mestrado profissional Profletras cumpriu uma tripla função: identificar as dificuldades dos estudantes na Prova Brasil/ANRESC, identificar como o livro didático trabalha tais conteúdos e apresentar tais dados aos professores a fim de que estes possam compreender melhor o contexto de implantação das avaliações externas, os conhecimentos que são cobrados nela e as limitações e contribuições do livro didático neste sentido. A partir destas informações, os professores poderão reestruturar as suas aulas não com o simples objetivo de conseguirem uma melhor pontuação na citada prova, mas sim de desenvolver nos estudantes as habilidades e competências vitais para que estes possam se tornarem cidadãos críticos, ainda que a melhoria na aprendizagem possa melhorar a nota, o objetivo é melhorar a aprendizagem.

Atualmente, as avaliações externas têm se apresentado como o principal instrumento para aferir a aprendizagem dos alunos e fornecer dados para que gestores e professores possam realizar um diagnóstico da aprendizagem a partir dos resultados obtidos. No Brasil, coexistem a prática de avaliações internas e externas, entre elas a Prova Brasil, por meio dela, a comunidade escolar pode refletir sobre os fatores envolvidos em seu contexto que contribuíram para os resultados e tomar medidas para atingir patamares aceitáveis no desenvolvimento cognitivo de seus estudantes. Tal prova é um importante instrumento de avaliação externa que visa determinar o desempenho de alunos e escolas, além disso, seus resultados podem subsidiar ações em prol da melhoria da educação.

Os resultados da Prova Brasil foram extraídos do Instituto Nacional de Estudos e Pesquisas Educacionais Anísio Teixeira (Inep), vinculado ao Ministério da Educação (MEC), no site do referido instituto, foram encontrados os descritores da Prova Brasil, doravante PB, de Língua Portuguesa.

O primeiro passo desta pesquisa foi determinar quais os descritores da Prova Brasil apresentaram maior grau de dificuldade para os alunos, em seguida, foi investigado como o 
livro didático abordava estes descritores para em seguida transformar estes dados num minicurso destinado aos professores da escola.

Os critérios adotados para classificar esta pesquisa se pautaram nos delineamentos apresentados por Gil (2010) e Severino (2007), referentes ao campo das ciências humanas. A metodologia empregada levou em consideração a abordagem teórica e a análise dos dados, por isso pôde ser classificada como um estudo de caso. Segundo Gil (2010, p. 37) esse procedimento apresenta "um delineamento mais adequado para a investigação de um fenômeno contemporâneo dentro de um contexto real", visto que tomamos os resultados de uma determinada escola como fonte de referência e um único material didático como objeto de nossa análise.

Em relação à técnica de pesquisa empregada neste estudo, a análise de dados foi feita a partir de uma abordagem qualitativa e de caráter descritivo-explicativo, pois de acordo com Gil (2010, p. 28), é possível, por meio da pesquisa explicativa, identificar a razão das coisas, ou seja, ela aponta os fatores que "determinam ou contribuem para a ocorrência de fenômenos", sendo assim possível que busquemos o entendimento das questões abordadas. Foram adotados também procedimentos de análise quantitativa com o objetivo de determinar a porcentagem de acertos e o número de descritores identificados no corpus da pesquisa.

De acordo com Severino (2007, p. 102), “a primeira atividade do cientista é a observação dos fatos", por isso, inicialmente, averiguamos os resultados da última PB em uma escola estadual de uma cidade do Norte do Paraná e verificamos quais os níveis de proficiência apresentados em Língua Portuguesa. Esta instituição foi escolhida por ter obtido resultados abaixo da meta estabelecida. Seu IDEB (Índice de Desenvolvimento da Educação Básica) caiu de 4.0 por três anos consecutivos para 3.2 em 2013. É uma escola de pequeno porte que atende a alunos de baixo poder aquisitivo e, por isso, o livro didático representa seu principal material de aprendizagem.

Visto não termos acesso a um exemplar dos cadernos de avaliação da $\mathrm{PB}$, devido ao sigilo exigido pela metodologia adotada pelo órgão, nosso corpus foi constituído pelos 93 itens de questões disponibilizadas na Plataforma Devolutivas Pedagógicas ${ }^{3}$, que tem como objetivo oferecer um retorno pedagógico sobre os resultados e dados das escolas que participaram da prova.

\footnotetext{
${ }^{3}$ A Plataforma Devolutivas Pedagógicas é uma ferramenta voltada para a consulta de gestores e professores que oferece uma análise dos itens da Prova Brasil e apresenta o desempenho dos alunos das escolas participantes. Disponível em: http://portal.inep.gov.br/plataforma-devolutivas. Acesso em: 5 jan. 2015.
} 
O livro didático adotado por esta instituição de ensino é composto de quatro volumes, destinados aos alunos de $6^{\circ}, 7^{\circ}, 8^{\circ}$ e $9^{\circ}$ anos, o seu título é Para Viver Juntos: Português, de autoria de Greta Marchetti; Heidi Strecker e Mirella Cleto (2009). Tal coleção foi escolhida em primeira opção pelo colégio em 2010 e foi utilizada nos anos de 2011, 2012 e 2013. Para a análise foi selecionado o livro destinado ao $9^{\circ}$. ano, por ser este ano/série destinado à avaliação pela PB. Por meio dessa análise, buscamos traçar um paralelo entre os conteúdos abordados no livro didático, doravante $\mathrm{LD}$, e os descritores da $\mathrm{PB}$, a fim de verificar se existia consonância entre aquilo que o LD ensinava e o que as provas avaliam.

Antes de apresentar os resultados, faz-se necessário fazer algumas considerações sobre a importância do LD dentro do ambiente escolar e sobre o papel que as avaliações externas estão desempenhando no contexto atual.

\section{O LIVRO DIDÁTICO COMO PRINCIPAL MATERIAL UTILIZADO PELO PROFESSOR}

Em sala de aula, o LD disponibiliza ao professor e aos alunos, uma variedade de textos e exercícios como base para a aprendizagem de conteúdos selecionados pelo autor. O LD tem assumido o papel de instrumento mediador da prática pedagógica, pois por meio dos conteúdos abordados se propõe a oferecer a alunos e professores os conhecimentos sócios-histórico mais importantes para cada ano de escolarização.

Coracini (1999, p. 34), complementa esta ideia e afirma que "é voz corrente e antiga que o livro didático constitui o centro do processo-aprendizagem em todos os graus de ensino, com ênfase no ensino fundamental e médio". De acordo com a pesquisa realizada pela autora entre professores de língua estrangeira e língua materna, quanto a aspectos metodológicos, linguísticos e ideológicos, os professores demonstraram ser favoráveis ao seu uso em sala de aula. O processo de legitimação do livro didático em um contexto escolar vem da ampla aceitação e reconhecimento de seu valor. É notório o papel estruturador que o LD desempenha em sala de aula. Mais do que isso, para Rojo e Batista (2003, p. 45), o livro didático deve atender as demandas pedagógicas da escola favorecendo a aprendizagem do aluno, tanto em relação aos conteúdos escolares, como também na compreensão da realidade que o cerca, a fim de instigá-lo a encontrar caminhos para uma transformação social.

De acordo com estes pressupostos, o LD deve ser pensado como um "subsídio da escola" na promoção da formação do cidadão. No entanto, por ter um caráter estruturador do 
trabalho pedagógico, muitas vezes, tem condicionado a ação docente. Isso não significa que o professor não possa fazer uso dessa ferramenta para o ensino, mas que pode ser seletivo e flexível em seu plano de trabalho, não delegando ao livro todo o trabalho pedagógico. Este será o ponto de partida empregado na discussão a ser realizada com os professores, quem vive a realidade da educação básica sabe a importância do LD e que não pode descartá-lo, mas sim devemos complementá-lo, fazer com que ele trabalhe a nosso favor e não o contrário, estas reflexões advindas do Profletras devem ser socializadas com todos os professores, desta forma, pensamos que estamos multiplicando o impacto do programa, pois ele não proporcionou só a reflexão do mestrando, mas de todos com que ele trabalha na sua escola de origem, muitas vezes, enquanto professores estamos tão presos a nossa prática que não conseguimos refletir sobre ela, o mestrado profissional, diferentemente do acadêmico, nos propõe repensar a nossa própria prática, mais do que isto este estudo pretende disseminar esta reflexão com todos os professores de língua portuguesa da escola.

Podemos concluir que o LD ocupa um papel de destaque no ensino, porém precisa ser utilizado de forma criteriosa para favorecer a aprendizagem e não deve condicionar ou limitar a ação docente a seus conteúdos, visto que cabe a equipe docente planejar o trabalho pedagógico, esta reflexão inicial será de grande valia para todo o corpo docente da escola.

\section{AS AVALIAÇÕES EXTERNAS COMO INSTRUMENTOS PROMOTORES DA QUALIDADE}

No contexto educacional brasileiro, a prática das avaliações internas e externas são comuns no cotidiano escolar. Classificam-se como avaliações internas aquelas elaboradas pelo professor ou pelas instituições de ensino com o objetivo de determinar se os alunos assimilaram os conteúdos abordados a cada etapa do processo de ensino/aprendizagem e/ou se terão condições de passar para a série/ano seguinte. Por sua vez, as avaliações externas são elaboradas por profissionais ou firmas de consultoria especializadas externas à escola com objetivo de fazer um diagnóstico do sistema de ensino no país e avaliar uma instituição como um todo ou parte de suas ações (WERLE, 2010). Esse tipo de avaliação utiliza, mais frequentemente, testes compostos por itens de múltipla escolha por meio dos quais apenas uma habilidade é avaliada por vez. 
É possível afirmar que nas últimas décadas houve um aumento no espaço ocupado pelas avaliações externas na Educação Básica brasileira. De acordo com Bonamino e Sousa (2012), foi no final dos anos de 1980 que esse tipo de avaliação passou a integrar políticas e práticas governamentais, a fim de se organizar um sistema de avaliação em âmbito nacional, muitas vezes o professor da escola pública não se dá conta desta proliferação e do quanto ela influencia o seu trabalho pedagógico, por isso a importância de propormos esta reflexão no segundo momento da nossa intervenção com os professores. De acordo com Afonso (2007), as avaliações acabam servindo de instrumento classificatório em função da necessidade de apresentação obrigatória de um resultado final que qualifica o aluno e a instituição de ensino.

No entanto, apesar da publicação do IDEB criar uma competição e um ranqueamento entre as instituições de ensino e do interesse político envolvido nas avaliações externas, tais dados podem levar a reflexão sobre o nível de nossos alunos e repensar nossa prática pedagógica, pois como bem salienta Corrêa (2012, p. 47), "não basta garantir o acesso à escola, é primordial oferecer um ensino de qualidade para todos, mas para isso é necessário saber que tipo de ensino é oferecido e em que condições se encontra a escola pública. ”

É preciso superar esta competição/ranqueamento e utilizar os resultados das avaliações para repensar a aprendizagem dos alunos, neste caso, analisar o papel do LD como um instrumento a favor da aprendizagem. Avaliar é inerente ao ato pedagógico e não tem uma finalidade em si mesma, senão no uso que faz dos resultados apresentados, por isso é preciso redirecionar estes usos de forma que fomente iniciativas a favor da aprendizagem. Apresentar a avaliação como uma política pública classificatória é um passo importante, mas não nos limitaremos a ele, é igualmente importante que o professor supere a crítica e consiga ver um potencial educativo nestas avaliações, afinal elas sistematizam dados importantes sobre os nossos alunos e a sua aprendizagem, é com este enfoque que analisamos a articulação da PB com o LD.

\section{COMPARAÇÃO ENTRE A PROVA BRASIL E O LIVRO DIDÁTICO}

A fim de evidenciar a relação entre os descritores da PB e a forma que o LD trata do mesmo descritor, comparamos os dois objetos por meio de exemplos de atividades, trazemos itens utilizados na PB seguidas do percentual de acertos acompanhados de alguns "comentários pedagógicos" adaptados do site do Inep. Apresentamos ainda o resultado de nossa análise das 
questões presentes no livro didático utilizado pelos alunos durante o ano em que ocorreu a avaliação.

O estudo referente as questões têm como objetivo analisar o que é trabalhado com os alunos no $\mathrm{LD}$, visto que o material intermedeia as ações de ensino e aprendizagem, consequentemente, serve de parâmetro para os alunos, pois serão essas representações que eles devem esperar encontrar em avaliações de Língua Portuguesa. Vale ressaltar que buscamos identificar se os descritores subjacentes às questões cobrados na Prova Brasil aparecem no livro didático e como são tratados, desta forma, focamos nos descritores e não nos gêneros geradores das questões.

Gráfico 01 - Gêneros discursivos utilizados na Prova Brasil.

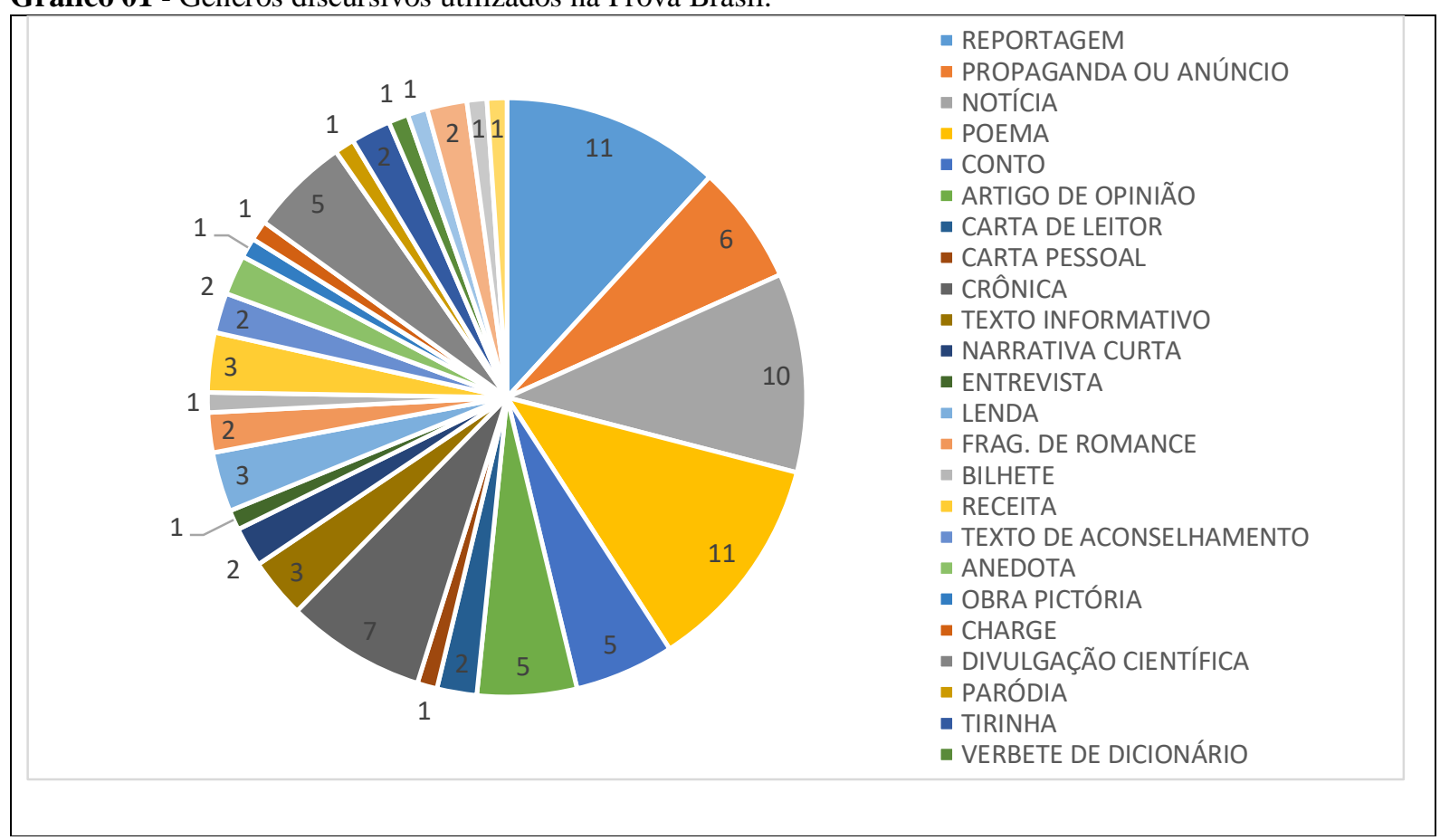

Fonte: O próprio autor, a partir dos gêneros presentes na Prova Brasil.

De acordo com os dados apresentados, os gêneros mais recorrentes nas questões da Prova Brasil são reportagem (11), poema (11), notícia (10), crônicas (7), propaganda ou anúncio (6), artigo de opinião (5), artigo de divulgação científica (5) dentre outros, esta informação é importante para o professor da educação básica.

Já no livro didático do $9^{\circ}$ ano, encontramos os seguintes gêneros principais que definem a exploração dos elementos composicionais dos textos: contos (psicológico, social e de amor), crônica esportiva, reportagem, artigo de divulgação científica, verbete de enciclopédia, texto dramático, roteiro, propaganda e resenha crítica. Outros gêneros são 
apresentados em outras unidades da coleção, mas não podemos afirmar que todos os alunos tiveram acesso a eles.

Ao observar os resultados dos 93 itens disponibilizados, inicialmente, identificamos em nossa análise de dados os 34 descritores que tiveram uma média inferior a 50\% de acertos. Dentre estes, destacamos aqueles com maiores percentuais de dificuldade para os alunos que realizaram a PB (menos de $35 \%$ de acertos), foram eles:

(D3) Inferir o sentido de uma palavra ou expressão. Tal descritor estava presente em três questões;

(D5) Interpretar texto com auxílio de material gráfico diverso (propagandas, quadrinhos, foto, etc.), presente em duas questões;

(D13) Identificar as marcas linguísticas que evidenciam o locutor e o interlocutor de um texto, presente em quatro questões;

(D15) Estabelecer relações lógico-discursivas presentes no texto, marcadas por conjunções, advérbios, etc, presente em duas questões.

A fim de averiguar como tais conhecimentos/descritores foram trabalhados no LD, foi realizada a comparação entres os dois suportes: Prova Brasil e Livro Didático.

Quadro 01 - Comparação entre PB e LD - Descritor D3

\begin{tabular}{|c|c|}
\hline Prova Brasil & Livro Didático - $9^{\circ}$ ano \\
\hline Inferir o sentido de uma palavra ou expressão. (D3) & Seção: A Linguagem do texto \\
\hline $\begin{array}{l}\text { Prejuízo em estacionamento } \\
\text { Sou freqüentador quase que diário do } \\
\text { estacionamento de um shopping explorado por uma } \\
\text { empresa. No último dia } 21 \text { estacionei à tarde e à } \\
\text { noite. Quando saí à noite, notei que o rádio do meu } \\
\text { carro estava funcionando mal, motivado pelo roubo } \\
\text { da antena. No dia seguinte, preenchi um formulário } \\
\text { anexando os dois comprovantes do pagamento, } \\
\text { solicitando a reposição da antena, pleito que me foi } \\
\text { negado dois dias após, por telefone. Fiz outro } \\
\text { requerimento solicitando uma justificativa da } \\
\text { negação e não fui atendido. Qual o direito que temos } \\
\text { ao estacionar em um shopping pagando R\$ } 2,50 \text { ? } \\
\text { Texto adaptado. O GLOBO: } 21 \text { de jan. de } 2001 \text {, pág. } 32 \text {. } \\
\text { A palavra “pleito", no texto, refere-se } \\
\text { (A) ao roubo da antena. } \\
\text { (B) à reposição da antena. } \\
\text { (C) à justificativa da negação. }\end{array}$ & 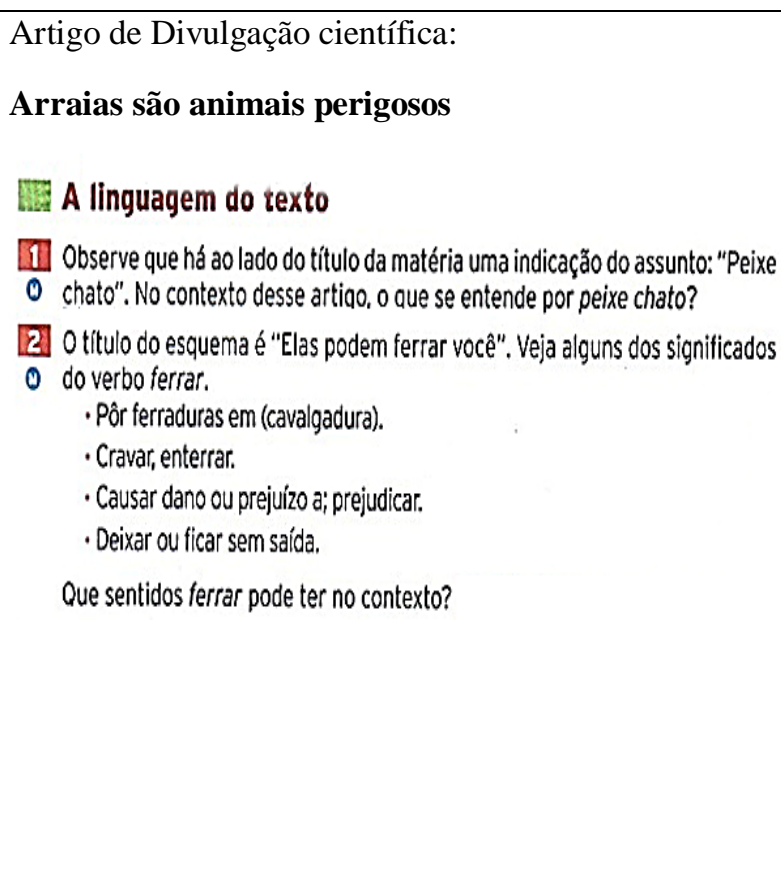 \\
\hline
\end{tabular}


(D) ao comprovante do pagamento.

3. 0 emprego de palavras do título que, no contexto, podem ser entendidas de - duas maneiras é intencional.

a) Essa ambiguidade torna 0 artigo mais informal ou mais formal?

b) No corpo do artigo também há frases ambíquas? Por que isso ocorre?

A linguagem dos artigos de divulgação cientifica deve ser precisa e objetiva, mas também acessivel a leitores leigos, nảo especialistas na área.

Quando o artigo é publicado em revista, ao lado do objetivo de transmitir conteúdo cientifico existe o de entreter. Para isso, muitos textos desse género fazem uso de recursos próprios da linguagem informal.

44 artigo de divulgação científica, além de apresentar imagens, também recorre

- a comparações para tornar os conteúdos mais compreensiveis ao leitor. A que o texto compara os elementos a seauir?

- 0 ferrão.

- O serrilhado do ferrão.

- As serrilhas reversas.

- A cauda.

[5] Além das imagens e comparações, nesse gênero, é muito importante o emprego de vocábulos específicos. Encontre exemplos no texto.

Fonte: http://devolutivas.inep.gov.br/itens publicados/30. Acesso em: 29 abr. 2016.
Fonte: MARCHETTI, Greta, STRECKER, Heidi, CLETO, Mirella L. Para viver juntos: Português, $9^{\circ}$ ano; Ensino Fundamental. P. 117.

Este item da PB foi utilizado para avaliar a habilidade dos alunos em identificar o referente de uma palavra no texto. Observamos que o enunciado é de curta extensão e de fácil compreensão. O gênero textual é uma carta de leitor dirigida a um jornal e publicada em seção própria para esse tipo de correspondência. Normalmente, esse gênero tem caráter argumentativo, pois seu objetivo é apresentar demandas pessoais ou expressar um posicionamento a respeito de um fato, sendo mais usada em contexto jurídico. Para responder corretamente à questão, é preciso determinar o significado da palavra "pleito" por meio de um referencial no texto. De acordo com os resultados, o item apresentou um índice de acerto de apenas 33\% e uma grande dispersão entre os três distratores.

Esse descritor é trabalhado na seção no LD na seção "A linguagem do texto", que tem por objetivo destacar os recursos linguísticos e gramaticais usados para criar efeitos de sentidos em textos de diferentes gêneros. Na atividade exemplificada, o enunciado da questão pede que o leitor observe os elementos extralinguísticos como a ilustração e as legendas que acompanham o artigo de divulgação científica para entender corretamente o sentido do adjetivo "chato" e do verbo "ferrar". Visto que a palavra "chato" tem duplo sentido, poderia ser entendida como desagradável ou fazer referência ao formato do peixe. 
A questão 2 traz alguns significados do verbo ferrar que oferecem opções à compreensão, a expressão também apresenta uma ambiguidade gerada pelo uso coloquial de "ferrar" no sentido de "prejudicar", que pode ser sanada por meio da leitura e do contexto.

Ao compararmos o tratamento dado na PB ao descritor D3 com a forma apresentada no LD, observamos que há pontos em comum, pois ambos trabalham com a inferência do significado de uma palavra pelo seu contexto. Os enunciados são diretos e simples não deixando margem para dúvida sobre o que está sendo solicitado. No entanto, a questão da PB não oferece os possíveis significados dos vocábulos como no $\mathrm{LD}$, o que, obrigatoriamente, exigiria do aluno uma segunda leitura do texto para tentar inferir o significado. O que muitas vezes não ocorre devido ao tempo reduzido de uma avaliação ou mesmo o desinteresse de muitos alunos.

A nossa primeira hipótese era de que se o descritor fosse trabalhado pelo LD o estudante teria o conhecimento prévio para apresentar um bom desempenho na PB, contudo tal premissa não se confirmou uma vez que esse tipo de exercício é trabalhado exaustivamente pelo LD e, mesmo assim, não foi suficiente para garantir um bom desempenho dos estudantes, o que nos leva a crer que outros fatores podem ter interferido na aprendizagem ou na interpretação da questão. O mesmo raciocínio pode ser aplicado às demais questões.

Quadro 02 - Comparação entre PB e LD - Descritor D5

\begin{tabular}{|l|l|}
\hline Prova Brasil & Livro Didático - 90 ano \\
\hline $\begin{array}{l}\text { Interpretar texto com auxílio de material } \\
\text { gráfico diverso (propagandas, quadrinhos, } \\
\text { foto, etc.). (D5) }\end{array}$ & Seção: Estudo do texto \\
\hline Questão 139 - Nível 7 & Exemplo p. 196 \\
\hline $\begin{array}{l}\text { O Brasil na pindaíba } \\
\text { (Vladimir Brandão) }\end{array}$ & Propaganda \\
\hline
\end{tabular}




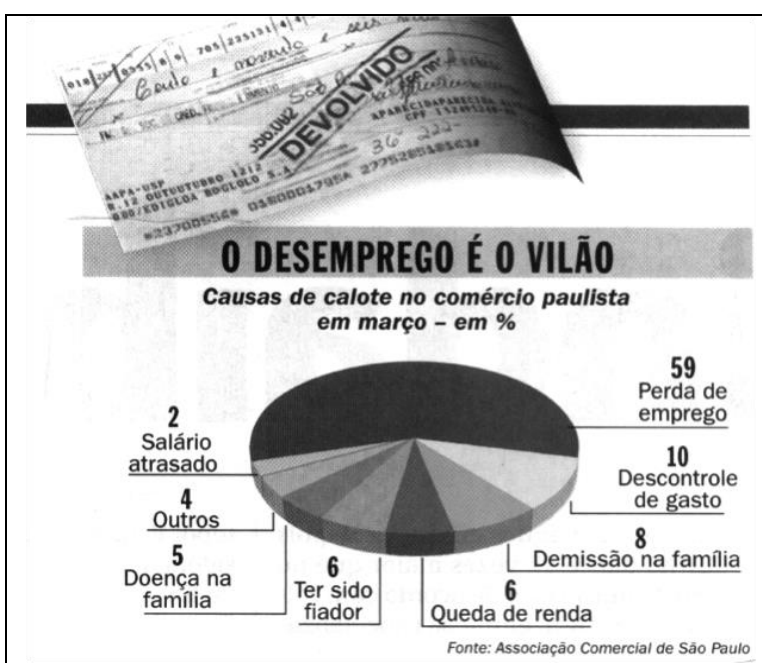

O baiano Carlos Cajazeira, de 39 anos, salário de R\$ 350,00 espalhou cheques voadores por lojas, supermercados e, mais recentemente, até pela escola da filha. Cajazeira é um dos milhões de brasileiros atropelados pela bola-de-neve da inadimplência. Seus pré-datados que pagaram móveis para o apartamento de Salvador começaram a voltar há seis meses, quando a despesa extra uma hospitalização da filha de 3 anos - sangrou de vez suas finanças. Não teve jeito. Os cheques que Cajazeira assinou e não honrou somam R\$1.500,00 e passaram a engrossar a estatística que assusta o país: nunca tantos cheques foram devolvidos por falta de fundos como no mês de março. A média do primeiro trimestre foi $23 \%$ maior que a média do mesmo período de 2001.

(BRANDÃO, Vladimir. Revista Época, n. 206, 29 abr.2002. pp. 68-70.)

De acordo com o texto, A PRINCIPAL causa do calote no comércio paulista foi a

(A) queda de renda.

(B) doença na família.

(C) perda do emprego.

(D) demissão na família.

Fonte: http://devolutivas.inep.gov.br/itens_ publicados/139. Acesso em: 29 abr. 2016.

\section{Etodoctorto}

Observe a imagem ao lado.

- a) Essa propaganda homenageia os profissionais especialistas em nutrição. Que elementos do texto fazem referência a essa profissão?

b) No texto aparecem palavras cujos sons se repetem. Quais são elas?

c) Localize um neologismo no texto e explique sua formação.

d) Que efeito de sentido 0 uso dessa palavra provoca na propaganda?

Octopus Comunicaçōes / De Nadai

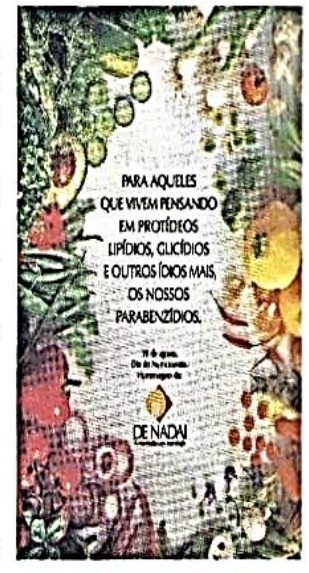

Texto da propaganda:

"Para aqueles que vivem pensando em protídeos, lipídios, glicídios e outros ídios mais, os nossos parabenzídeos."

\section{1 de agosto}

Dia do Nutricionista

O item da prova avalia a habilidade do aluno interpretar informações com base na leitura de uma informação constituída por uma fotografia de um cheque com carimbo de devolvido, um gráfico em formato de pizza e uma notícia. O texto requer leitura não linear e compreensão de dados estatísticos. Apresenta algumas metáforas para tratar da temática 
"cheques voadores", "atropelados pela bola de neve da inadimplência" e "sangrou suas finanças", além de alguns termos técnicos como "inadimplência" e regionais "calote, pindaíba", que podem ter tornado a compreensão do texto mais difícil.

O enunciado solicita a identificação de uma informação contida no texto, mas não especifica em que parte dele. Apesar da resposta ser obtida pela análise dos dados contidos no gráfico, a leitura da notícia exigiria a combinação dos diferentes tipos de informação. O que pode ter dificultado a resposta correta dos alunos é o fato de muitos não reconhecerem um gráfico como sendo um texto e que levaria o estudante a buscar a informação apenas no texto verbal. O item apresentou apenas $31 \%$ de acertos.

Tal descritor também é trabalhado no LD, o exemplo selecionado traz uma propaganda, gênero discursivo que geralmente associa imagem e texto verbal. Podemos observar a forma que as questões são elaboradas a fim de chamar a atenção do leitor para a imagem da propaganda, "observe a imagem ao lado". A homenagem feita aos especialistas em nutrição só poderá ser plenamente compreendida se a ilustração for observada em conjunto com o texto verbal, um complementando o outro. A questão (A) indaga sobre "que elementos do texto fazem referência a essa profissão? " A resposta esperada seria os alimentos da ilustração, o aluno precisa ter isso bem claro para não se limitar apenas ao texto verbal, tal como o exigido na PB.

Ao compararmos o item do descritor D5 cobrado na PB com a forma apresentada no $\mathrm{LD}$, podemos constatar que o LD apresenta questões relacionadas a linguagem verbal e não verbal na construção dos sentidos do texto, sendo necessária a articulação destes níveis de leitura. Conforme Solé (2009, p. 24), o bom leitor precisa ir além da decodificação, é necessário que aprenda a "processar o texto e todos os seus elementos, assim como as estratégias que tornaram possível sua compreensão", deve ainda ser capaz de articular as informações advindas de diferentes suportes a fim de compreender o objetivo e a mensagem que está sendo disseminada.

Quadro 03 - Comparação entre PB e LD - Descritor D13

\begin{tabular}{|l|l|}
\hline Prova Brasil & Livro Didático - 9 $\mathbf{a n o}$ \\
\hline $\begin{array}{l}\text { Identificar as marcas linguísticas que evidenciam o } \\
\text { locutor e o interlocutor de um texto. (D13) }\end{array}$ & Seção: Oralidade e Língua Viva \\
\hline Questão 154 - Nível 6 & Exemplo p. 169 \\
\hline
\end{tabular}




\section{O bem do mar \\ Dorival Caymmi}

O pescador tem dois amores

Um bem na terra, um bem no mar

$\mathrm{O}$ bem da terra é aquele que fica

$\mathrm{Na}$ beira da praia quando a gente sai

$\mathrm{O}$ bem da terra é aquele que chora

Mas faz que não chora quando a gente sai

O bem do mar, é o mar, é o mar

Que carrega com a gente

Pra gente pescar

(SALMASO, Mônica. Trampolim. Leoleo

Music/Marola.)

\section{O uso de linguagem coloquial está acentuado no} verso

(A) "O pescador tem dois amores".

(B) "O bem da terra é aquele que fica".

(C) "O bem do mar, é o mar, é o mar".

(D) "Pra gente pescar".

\section{(1) Here}

Woy Concordencia nominale expressividade

1. Leia o trecho da música.

Ispinho e fulô

É nascê, vivê e morrê

Nossa herança naturá .

Todos tem que obedecê

Sem tê a quem se quexá,

Foi o autô da Natureza

Com o seu pudê e grandeza

Quem traçou nosso caminho,

Cada quá na sua estrada

Tem nesta vida penada

Pôca fulô e muito ispinho.

Até a propa criança.

Tăo nova e tão atraente

Conduzindo a mesma herança

Sai do seu berço inocente,

Se passa aquele anjo lindo

Hora e mais hora se rindo

$E$ algumas horas chorando,

É que aquela criatura

Já tem na inocença pura

Ispinho the cutucando.

Fora da infança querida

No seu uso de razão

Vê muntas fulô caída

Machucada pelo chão,

Pois vê neste mundo ingrato

Injustiça, assassinato

Euns aos outros presseguindo

E assim nós vamo penando

Vendo os ispinho omentando

E as fulô diminuindo.

Patativa do Assaré, sspinho e futô. São Paulo: Hedra, 2005. p. 25-26.

a) Que ideia a respeito da vida está presente na primeira estrofe do poema? b) Para comprovar essa ideia, o poema vai descrevendo os vários estágios da vida. Quais são abresentados na seaunda e terceira estrofes?

A variedade linguística utilizada pelo poeta é caracterizada pelo registro, na escrita, de formas típicas da linguagem oral.

a) Como são reqistrados no dicionário os substantivos presentes no título?

b) Outras palauras recebem gratia diterente da que é prescrita pela norma-padrão. Encontre no texto exemplos de: supressão do $r$ final, supressão do I final e supressão do i dos encontros vocálicos.

13. A poesia matuta reflete o pensamento e a linguagem do homem do campo. Observe os versos abaixo.

"Vendo os ispinho omentando

E as fulô diminuindo."

a) Além das peculiaridades ortográficas, qual é a peculiaridade sintática que se pode observar nesse fragmento?

b) De acordo com a norma-padrão, a concordância nominal se dá em gênero (masculino / feminino) e em número (singular / plural). Nos exemplos analisados, qual desses itens recebe tratamento diferente daquele proposto pela normá?

O desvio da norma-padrão no que diz respeito à concordância nominal pode ser um recurso expressivo para caracterizar o grupo social ao qual pertence o eu lirico, o narrador ou uma personagem.

Fonte: http://devolutivas.inep.gov.br/itens publicados/154. Acesso em: 19 mai. 2016.
Fonte: MARCHETTI, Greta, STRECKER, Heidi, CLETO, Mirella L. Para viver juntos: Português, $9^{\circ}$ ano; Ensino Fundamental. P. 169.

O item da PB avalia a habilidade do aluno em identificar marcas linguísticas em uma letra de música. O texto base é uma canção popular e o enunciado indica que em um verso há o uso coloquial da linguagem, dando quatro opções. Não oferece complexidade, mas para o 
aluno entender a questão é preciso que conheça o conceito de linguagem coloquial. A proporção de acertos do item foi de apenas $24 \%$.

A variação linguística também é abordada pelo LD na seção "Oralidade" e "Língua Viva", por meio de vários gêneros discursivos, como poema, música, anúncio, carta, notícias e outros. Tal temática integra o currículo oficial e aparece como um dos temas a serem desenvolvidos. As atividades do LD exigem do aluno a habilidade em identificar as variações linguísticas resultantes da influência de diversos fatores como, o grupo social a que o falante pertence, determinado lugar e a época, bem como verificar quem fala no texto e a quem este se destina, reconhecendo as marcas linguísticas expressas por meio de registros usados, vocabulário empregado, uso de gírias ou expressões em diversos níveis de linguagem.

O exemplo destacado no $\mathrm{LD}$, assim como na $\mathrm{PB}$, é do gênero letra de música (poema), já no título apresenta duas palavras usadas de forma coloquial, "ispinho e fulô". Ao longo das estrofes, percebemos que há um acentuado desvio da norma padrão que se justifica pela intenção do autor em representar a fala do homem simples do campo. A vida nordestina e a condição humana são retratadas de forma poética numa representação da variação linguística regional com grande sonoridade.

As questões referentes ao texto destacam a forma como as palavras são utilizadas na linguagem oral de uma determinada região, "a poesia matuta reflete o pensamento e a linguagem do homem do campo", e as atividades conduzem a grafia de acordo com o registro do dicionário (2a), "Como são registrados no dicionário os substantivos presentes no título?".

A questão (2b) chama a atenção do aluno para o processo que desencadeou tal variação, "Outras palavras recebem grafia diferente da que é prescrita pela norma-padrão. Encontre no texto exemplos de: supressão do $r$ final, supressão do 1 final, e supressão do i dos encontros vocálicos.” A questão proposta não usa o termo coloquial e posteriormente não explica que esse processo não é exclusividade do falar caipira. Como aponta Bagno (2007), a redução dessas letras é uma característica comum de todas as variedades linguísticas brasileiras.

Este tipo de exercício que busca relacionar a linguagem coloquial a norma padrão é bastante comum no material didático analisado. No entanto, poemas como o de Patativa do Assaré, na concepção de Bagno (2007, p. 120) "não são representações fiéis das variedades linguísticas que supostamente veiculam", são representações artísticas sem "nenhum compromisso com o rigor da pesquisa científica," visto que as representações fieis só poderiam ser feitas por meio de transcrições fonéticas. Segundo os PCN, "No ensino-aprendizagem de 
diferentes padrões de fala e escrita, o que se almeja não é levar os alunos a falar certo, mas permitir-lhes a escolha da forma de fala a utilizar, considerando as características e condições do contexto de produção”. (BRASIL, 1998, p. 31).

Na PB não é pedida a "reescrita" ou qualquer outro tipo de "correção", contudo a expressão abreviada "pra” pode ser considerada de difícil identificação para os alunos, pois seu uso pode também ocorrer em contexto de formalidade relativa. A supressão de alguns fonemas é um processo muito comum na oralidade, precisamos atentar para essa particularidade da língua e conscientizar os alunos sobre essa particularidade.

\section{Considerações finais}

A aprendizagem dos alunos é uma preocupação constante de todos os envolvidos com a educação, dessa maneira, a busca pela melhoria na qualidade do ensino tem mobilizado ações, investimentos e políticas públicas para a superação das dificuldades, um dos caminhos desta superação é investir na formação continuada dos professores, tendo isto como base, podemos afirmar que esta pesquisa só foi possível graças ao Profletras, foi o olhar de professor da rede pública de ensino que direcionou a escolha do objeto de estudo, foi este mesmo olhar que guiou todas as etapas desta pesquisa e guiará os próximos, pois este estudo não se encerra aqui, ele repercutirá na prática de cada professor da escola e se espalhará por outras escolas, uma vez que muitos lecionam em diversas unidades escolares, entender o potencial e as limitações do LD pode ajudar não só os professores a melhorarem as suas práticas, mas os próprios estudantes a compreenderem melhor a complexidade da língua que utilizamos.

$\mathrm{Na}$ análise do LD, constatamos que os descritores da PB são trabalhados de forma implícita e integrados as atividades das seções dos capítulos, porém não encontramos atividades de múltipla escolha assim como na prova.

Segundo o que prescreve os PCN, a prática de leitura e escrita é fundamental em sala de aula, por isso nossa proposta de intervenção é mostrar aos professores o que investigamos e propor que estes criem situações em contextos reais que permitam reproduzir situações concretas de interação com o texto, com atenção para a relação entre produtores e receptores. Devido à grande diversidade de atividades comunicativas, as possibilidades de uso dos gêneros do discurso são infinitas e surgem de acordo com uma necessidade específica de interação do ser humano, por isso é importante que os alunos compreendam as implicações de se utilizar os 
diferentes gêneros de forma adequada, quando esses conceitos se tornam mais claros para o aluno a relação com a linguagem pode se tornar menos desafiadora.

Os gêneros discursivos são instrumentos no processo de aprendizagem das práticas sociais, como observado tanto nos itens da Prova Brasil como no livro didático são amplamente abordados seus elementos composicionais, a ideologia presente e suas implicações na construção de sentidos. Por meio de práticas de leitura, o professor pode promover o acesso dos alunos aos materiais impresso como, jornais, revistas, ilustrações, textos literários para que assim fiquem imersos numa variedade de textos e possam interagir com as diferentes práticas discursivas, para que isto aconteça, pretendemos apresentar os dados que levantamos a todo corpo docente da escola, assim eles terão uma outra visão da Prova Brasil e dos conhecimentos que ela cobra e do potencial do LD para atender estas exigências.

Visto que a PB é uma avaliação em larga escala e que envolve alunos de $9^{\circ}$ ano, o professor pode ter acesso aos itens da prova, os descritores cobrados e os distratores mais assinalados, a fim de conhecer as dificuldades de seus alunos. Precisamos refletir sobre a importância e a pertinência de se dominar certos saberes e compreender os impactos desses exames na realidade escolar, não para que o aluno alcance uma determinada nota, mas para que tenha acesso a outros materiais além do LD e expanda seu conhecimento de forma prática, o papel do professor nesta tarefa é primordial, o Profletras possibilitou que o primeiro passo fosse dado, continuaremos caminhando como professores da rede pública que, após esta experiência, compreendem muito melhor a criação das avaliações externas, os seus objetivos e o seu potencial para melhorar a qualidade de ensino do país.

\section{Referências}

AFONSO, Almerindo Janela. Estado, políticas educacionais e obsessão avaliativa. Contrapontos - volume 7 - n. 1 - p. 11-22 - Itajaí, jan/abr 2007. Disponível em: http://www6.univali.br/seer/index.php/rc/article/view/888/741. Acesso em: 26 dez. 2015.

BAGNO, Marcos. Nada na língua é por acaso: por uma pedagogia da variação linguística. São Paulo: Parábola, 2007.

BATISTA, Antônio A. Gomes; ROJO, Roxane; ZÜÑIGA, Nora Cabrera. Produzindo livros didáticos em tempos de mudança. In: VAL, Maria da Graça Costa; MARCUSCHI, Beth (orgs.). Livros didáticos de língua portuguesa: letramento e cidadania. Belo Horizonte: Ceale; Autêntica, 2005. 
BONAMINO, Alicia; SOUSA, Sandra Zákia. Três gerações de avaliação básica no Brasil: interfaces com o currículo da escola. Educação e Pesquisa, São Paulo, v. 38, n. 2, p. 373-388, abr./jun. 2012.

BRASIL. Secretaria de Educação Fundamental. Parâmetros curriculares nacionais: língua portuguesa. Brasília: MEC/SEF, 1998.

CORACINI, Maria José Rodrigues Faria (Org.). Interpretação, autoria e legitimação do livro didático: língua materna e língua estrangeira. Campinas, SP: Pontes, 1999.

FREITAG, Bárbara; COSTA, Wanderley F. da; MOTTA, Valéria R. O livro didático em questão. 2. ed. São Paulo: Cortez, 1993

GIL, Antonio Carlos. Como elaborar projetos de pesquisa. 5. ed. São Paulo: Atlas, 2010.

MARCHETTI, Greta, STRECKER, Heidi, CLETO, Mirella L. Para viver juntos: português, $9^{\circ}$ ano; Ensino Fundamental. - 1. Ed. rev. - São Paulo: Edições SM, 2009.

SEVERINO, Antônio Joaquim. Metodologia do trabalho científico. 23. ed. São Paulo: Cortez, 2007.

SOLÉ, Isabel. Estratégias de leitura. Porto Alegre: Artmed, 2009.

WERLE, Flávia O. Corrêa (Org.). Avaliação em larga escala: foco na escola. São Leopoldo: Oikos; Brasília: Liber Livro, 2010. 